\title{
Temperature Programmed Reduction of a PdCu Bimetallic Catalyst via Atmospheric Pressure in situ STEM-EDS and in situ X-Ray Adsorption Analysis
}

\author{
Matthew A. Kulzick ${ }^{1}$, Eric Prestat ${ }^{2}$, Paul J. Dietrich ${ }^{1}$, Eric Doskocil ${ }^{1}$, Sarah J. Haigh ${ }^{2}$, M. Grace \\ Burke $^{2}$, Nestor J. Zaluzec ${ }^{3}$ \\ 1. BP Research Center, Naperville, IL, USA \\ 2. University of Manchester, School of Materials, Manchester UK \\ 3. EM Center, Center for Nanoscale Materials, Argonne National Laboratory, Argonne, IL.
}

Temperature programmed reduction (TPR) is a classical method for the analysis of metal catalysts but provides little detail of what is actually occurring in the system if other methods are not employed to determine which changes are taking place. Coupling TPR with in situ X-Ray absorption analysis allows specific changes in bulk metal oxidation state via analysis of the X-Ray absorption near edge structure (TPR-XANES) or particle size and alloy structure by analysis of the extended X-Ray fine structure.(TPR-EXAFS)[1]. Recently, it has become possible to observe temperature programmed reduction via in situ scanning transmission electron microscope (STEM) energy dispersive X-ray spectroscopy (XEDS) at hydrogen pressures up to one atmosphere [2]. This correlative study uses a combination of: TPR, XANES, XEDS and S/TEM methodologies to study the evolution of particle morphologies on a $\mathrm{PdCu} / \mathrm{TiO}_{2}$ catalyst and explain the reduction profile observed in the conventional TPR of this system. This catalyst is representative of a large group of bimetallic catalysts useful for a range of chemical conversions including catalytic reforming, hydrotreating, emissions controls, and biomass conversion.

The $\mathrm{PdCu}$ catalyst was prepared by incipient wetness co-impregnation of copper and palladium nitrates on titania followed by calcination to yield the unreduced form of the catalyst. Conventional STEM-high angle annular dark field (HAADF) images and XEDS elemental mapping (Figure 1) indicate that the catalyst comprises fairly large Pd containing particles (red) with smaller copper clusters (green) dispersed across the titania support. XANES spectra of the calcined material (Figure 2) indicate that both $\mathrm{Pd}$ and $\mathrm{Cu}$ are initially present as oxides. The TPR-XANES of the Pd (Figure $2 \mathrm{a}$ ) shows complete reduction to $\operatorname{Pd}(0)$ after room temperature hydrogen treatment and that the metal remains $\operatorname{Pd}(0)$ throughout the remaining temperature points. By contrast, the $\mathrm{Cu}-\mathrm{K}$ edge reduction profile (Figure 2b) shows a small degree of reduction at lower temperatures, likely due to $\mathrm{Cu}$ associated with the Pd clusters and that the sample contains both oxide and metallic $\mathrm{Cu}$ up to $250^{\circ} \mathrm{C}$. As the temperature increases, the spectra evolve towards the expected shape for $\mathrm{Cu}$ metal with the sample becoming fully reduced after hydrogen treatment above $350^{\circ} \mathrm{C}$. The $\mathrm{Cu}-\mathrm{K}$ edge spectra of the fully reduced catalyst does not match that of the bulk metallic $\mathrm{Cu}$ reference and suggests that the final form of the $\mathrm{Cu}$ is not bulk $\mathrm{Cu}$ particles, but rather nanoparticulate or alloyed form.

Figures 3 and 4 show the results of in situ STEM-XEDS for this catalyst and reveal fine details of the particle transformations. All analyses were done at one atmosphere gas pressure. Figure 3, collected in air at $100^{\circ} \mathrm{C}$, shows microstructure similar to Figure 1 . After introducing $\mathrm{H}_{2}$ and heating to $250^{\circ} \mathrm{C}$, nanoparticles were resolvable in the $\mathrm{Cu}$ distribution and migration of $\mathrm{Cu}$ to $\mathrm{Pd}$ was evident thus explaining the low temperature copper reduction seen in the $\mathrm{Cu}-\mathrm{K}$ edge $\mathrm{TPR}-\mathrm{Xanes}$. At $550^{\circ} \mathrm{C}$, where TPR XANES indicates that copper oxides are no longer present, discrete copper domains are formed with $\mathrm{Pd}$ particles generally containing $\mathrm{Cu}$ but at varying concentrations. The heterogeneity of the localized composition is striking. In many cases Janus particles (Figure 4) have formed with various degrees of phase separation between the two metals. 
These correlative measurements highlight the value of employing different yet complementary techniques toward the understanding of bimetallic catalyst systems. Whereas the XAS is a bulk technique giving an average over all atoms, including those of different elemental mixtures and particle morphologies, it does not distinguish changes to the morphologies or particle configurations as a result of treatment. Combining those results with the microscopy, which does not track the changes to the metal oxidation state as easily as XANES, allows for a more complete picture of particle synthesis and activation for the final, active form of the nanoparticle catalyst [3].

\section{References:}

[1] C Geantet and C Pichon in "Characterization of Solid Materials and Heterogeneous Catalysts vol. 1", eds. M. Che and J Verdrine, (Wiley-VCH Verlag Gmbh \& Co, Weinheim), (2012) p. 511

[2] E Prestat et al, Microsc. Microanal. 21(3) (2015), p. 247-248

[3] Research supported by EPSRC Grants \#EP/G035954/1 and EP/J021172/1, the DTR Agency Grant HDTRA1-12-1-003, the BP Innovation Fund and ICAM project at Manchester U.S. DoE, Office of Science, Contract No. DE-AC02-06CH11357 in the Electron Microscopy Center of the Center for Nanoscale Materials at Argonne National Laboratory
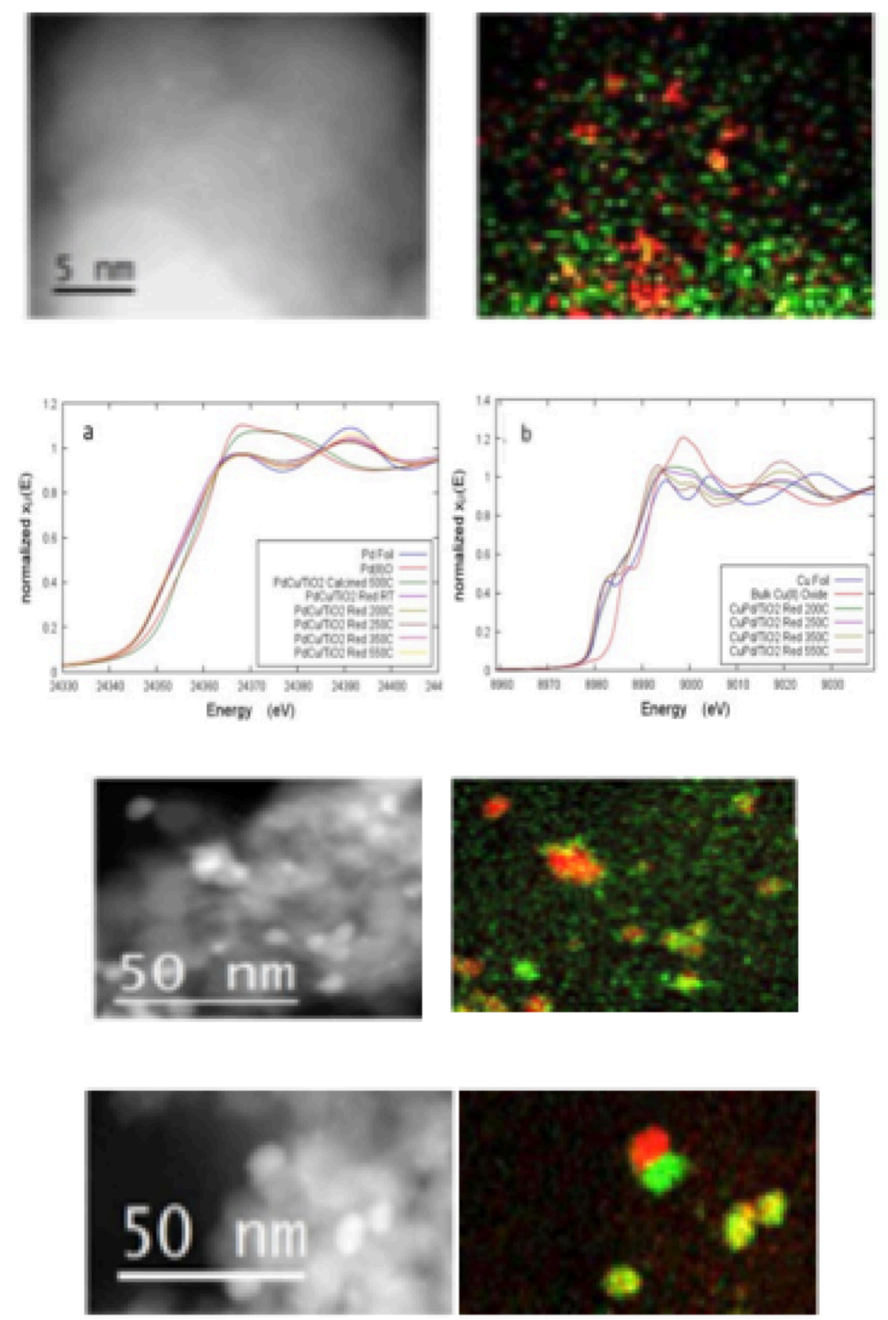

Figure 1. HAADF STEM and XEDS elemental mapping showing that the larger nanoparticles are Pd rich while the small metal clusters are principally made of $\mathrm{Cu}$. $\mathrm{Cu}=$ green, $\mathrm{Pd}=$ red.

Figure 2. XANES analysis of the $\mathrm{TiO}_{2}$ supported $\mathrm{PdCu}$ catalyst. (a) the $\mathrm{Pd}-\mathrm{K}$ edge for the starting material in air and for the material reduced in $\mathrm{H}_{2}$ (Red) vs temperature (b) $\mathrm{Cu}-\mathrm{K}$ edge of the starting material reduced in $\mathrm{H}_{2}$ compared to $\mathrm{Cu}$ foil and $\mathrm{Cu}(\mathrm{II}) \mathrm{O}$ reference materials vs temperature

Figure 3. STEM-HAADF and XEDS elemental maps for $\mathrm{Cu}, \mathrm{Pd}$ and combined $\mathrm{PdCu}$ are shown. at $100^{\circ} \mathrm{C}$ in air at $1 \mathrm{ATM}$, showing comparable microstructure to Figure 1.

Figure 4. HAADF STEM and XEDS elemental mapping showing that the larger NPs are Pd rich while the small metal clusters are principally made of $\mathrm{Cu}$ after heating $550^{\circ} \mathrm{C}$ in $\mathrm{H}_{2}$ 